\title{
A cartografia como estratégia metodológica à produção de dispositivos de intervenção na Psicologia Social
}

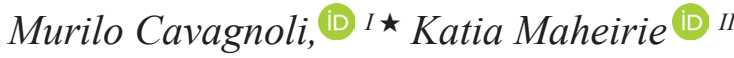 \\ ${ }^{I}$ Universidade Comunitária Regional de Chapecó, Chapecó, SC, Brasil \\ ${ }^{I I}$ Universidade Federal de Santa Catarina, Florianópolis, SC, Brasil
}

\begin{abstract}
Resumo
O artigo propõe desdobrar questões acerca da pesquisa-intervenção cartográfica visando contribuir para a construção de dispositivos de intervenção no trabalho da psicologia social. Considerando os desafios contemporâneos à psicologia, apresenta a cartografia como metodologia que engendra processos dialógicos, envolvendo pesquisadores e pesquisados na negociação de sentidos e ações que apreendam a complexidade do cotidiano. Desenvolve a possibilidade de que a cartografia contribua para a criação de dispositivos de intervenção singulares, potencializando uma ética dos encontros. Deste modo, afirmamos que os dispositivos cartográficos oferecem vias consistentes à elaboração de experiências relacionais que sustentam, caso a caso, um plano compartilhado de afecções, com o objetivo de dar vazão a movimentos de subjetivação criadores, problematizadores e transformadores da realidade, ao investir na potência do coletivo. As sínteses aqui produzidas reafirmam a indelével relação entre pesquisar e intervir, explorando conexões entre o método cartográfico, seus dispositivos e o compromisso social da psicologia, em uma perspectiva crítica.
\end{abstract}

Palavras-chave: cartografia; dispositivos de intervenção; psicologia social.

\section{Cartography as a methodological strategy in the production of intervention devices in Social Psychology}

\begin{abstract}
The paper proposes to unfold questions about cartographic intervention-research toward contributing to the construction of intervention devices in Social Psychology's work. Considering the contemporary challenges to Psychology, it presents cartography as a methodology that produces dialogical encounter, involving researchers and subjects in the negotiation of meanings and actions that grasp the complexity of everyday life. It develops the possibility of cartography to concur unique interventional devices, enhancing an ethic of encounters. Thus, we affirm that cartographic devices offer consistent ways to develop relational experiences that support, on a caseby-case basis, a shared plan of affections, with the objective of giving rise to creative movements of subjectivation, which problematize and transform that of reality, by invest in the collective power. Their syntheses reaffirm the lasting connection between researching and intervening, exploring connections between the method and the social commitment of Psychology, from a critical perspective.
\end{abstract}

Keywords: cartography; intervention devices; social psychology.

\section{Introdução}

Este artigo visa promover o desdobramento de algumas questões acerca da prática da pesquisa participante proposta pelo método cartográfico na direção de contribuir com a construção de estratégias de intervenção no trabalho da psicologia social. Afirmamos a necessidade de reinvenção constante de práticas e leituras teóricas no campo de atuação da psicologia em contextos institucionais, comunitários e coletivos, considerando as prementes demandas que o contemporâneo nos enseja a enfrentar. Em função de tais desafios, a perspectiva cartográfica de pesquisa (PASSOS; KATRUP; ESCOSSIA, 2009; PASSOS; KASTRUP; TEDESCO, 2014) e a noção de dispositivo - engendrada por Foucault (1984) em sua busca por visibilizar práticas disciplinares que capturam subjetividades, e posteriormente relida por Deleuze (1990) e Hur (2012), em sua potência de resistência - são aqui entendidas como peças-chave de um aparelho conceitual que permite o desenvolvimento de intervenções psicológicas. Visamos intervenções construídas coletivamente, que ultrapassem a reprodução e a representação,

\footnotetext{
^Endereço para correspondência: Universidade Comunitária Regional de Chapecó, Área de Ciências Humanas e Jurídicas. Av. Senador Attílio Fontana, 591-E Efapi, Chapecó, SC-Brasil. CEP: 89802-140.E-mails: murilocavagnoli@unochapeco.edu.br, maheirie@gmail.com
}

Os dados completos dos autores encontram-se ao final do artigo. em direção à afirmação das diferenças e à heterogênese característica dos movimentos de subjetivação. A pesquisa e a intervenção são situadas como processos indissociáveis que concomitantemente compreendem e forjam a realidade que se busca compreender. Consideramos estes dois movimentos, quando amalgamados, como mobilizadores da atividade criadora, em direção ao rearranjo de práticas, discursos e ações da psicologia em seus encontros com distintos cenários.

A psicologia, enquanto ciência e prática profissional, tem se constituído, historicamente, como um campo atravessado por variadas perspectivas que situam distintas propostas, erigidas sob planos epistêmicos, ontológicos e éticos distintos e divergentes (FIGUEIREDO, 1992). Tal dispersão da psicologia em diversos projetos caracteriza a complexidade desta ciência, colocando-a em debate constante.

Em meio a tal profusão peculiar do campo, ainda encontramos, na contemporaneidade, uma série de desafios sem precedentes às práticas do/a psicólogo/a, que clamam pela reinvenção de estratégias de intervenção e pela revisão de fundamentos. Dentre os dilemas epistemológicos e ontológicos que evidenciam a necessidade de se repensar os modos de compreender o mundo e o sujeito com o qual atuamos, é evidente a paulatina superação do 
projeto racionalista da modernidade, de filosofias calcadas na representação, das dicotomias entre objetividade e subjetividade e de uma suposta identidade portadora de essências (FREIRE, 2001).

A contemporaneidade, numa dimensão pragmática e existencial produzida pela sua lógica globalizada e capitalista, situa o sujeito em um conjunto de realidades radicalmente descontínuas no espaço e no tempo (HARVEY, 2013). O esvaziamento do espaço público e sua inundação pelo privado, assim como o culto à individualidade, o derretimento das instituições e a liquidez das relações (BAUMAN, 2001), criam um contexto no qual subjetividades inéditas passam a existir, carregando consigo antigas problemáticas e novos questionamentos e dilemas.

Outro ponto a destacar é a aceleração na velocidade das mudanças (GIDDENS, 1991), que radicaliza as diferenças e faz com que as variações escapem a um olhar despreocupado. Transformações nas relações com a comunidade, com a família, com as tecnologias, o Estado, o trabalho e o capital, resultam em uma profusão sem precedentes de distintas formas de ser e existir. O sujeito contemporâneo, em meio a este processo, pode ser conceituado como despido de uma identidade fixa, tornando-se a identidade uma "celebração móvel" (HALL, 2014, p. 24). A multiplicidade das experiências de ser na atualidade, portanto, torna indispensável a constante reflexão sobre nossos paradigmas e um investimento contínuo no desenvolvimento de metodologias que permitam a apreensão de um campo social multifacetado.

Compondo esta cena plural e complexa, encontramos no contexto brasileiro, desde a década de 1980, uma psicologia social que afirma historicamente um compromisso ético e político (LANE; CODO, 1985; CAMPOS, 1985; BOCK, 2009) com a transformação social, renunciando a um viés pragmático e funcionalista ${ }^{1}$ e investindo nas singularidades que, outrora, foram invisibilizadas, colocadas "à margem" do campo social. Pesquisadores contemporâneos, como Benevides (2005) e Zanella et al. (2012), insistem em criticar a simples transposição de práticas clássicas da psicologia como resposta ao cenário atual, apostando na produção de um trabalho ético e político, no qual a ética significa o acolhimento das alteridades na construção de projetos coletivos em condições de equidade, e a política remete à dimensão dialógica de negociação constante sobre os sentidos do campo social.

Em função da problemática apresentada, abordaremos alguns pressupostos da pesquisa cartográfica em diálogo com a noção de dispositivo de intervenção, considerando a seguir as potencialidades deste diálogo para a construção de práticas psicológicas comprometidas com

\footnotetext{
'Os termos "pragmático" e "funcionalista" são utilizados de forma semelhante por Bock (1999), Bernardes (2009) e Bock, Gonçalves e Furtado (2001), para caracterizar e criticar propostas da psicologia social produzidas em solo norte-americano, importadas da América Latina sem considerar as idiossincrasias de nossas terras. Esta tendência pragmática visava à resolução de conflitos e à adaptação de sujeitos considerados disfuncionais em contextos de produção e convivência pacífica, sem entender a possibilidade de que a emergência de tais problemáticas poderia estar amalgamada à constituição histórica de tais contextos, impedindo, assim, sua problematização mais profunda. Tais escritos, junto a muitos outros de importantes teóricos de nosso campo, ainda nos alertavam acerca da necessária revisão da concepção de sujeito e da fundação de um compromisso social que reorientasse a Psicologia Social no Brasil.
}

a reinvenção criativa dos modos de vida contemporâneos. O método cartográfico afirma a indissociabilidade entre pesquisar e transformar (PASSOS; BARROS, 2009). Por isso, argumentamos em favor da cartografia como possibilidade de construção teórico-prática de validação de estratégias de ação transversais à produção de dispositivos de intervenção que sejam capazes de contemplar a diversidade das demandas contemporâneas. Buscamos, assim, o delineamento de um suporte teórico ao engendramento de uma pesquisa-intervenção criativa, coerente com os princípios da psicologia social crítica construída no Brasil e na América Latina como um todo.

\section{O método cartográfico e a reinvenção de caminhos nos percursos de pesquisa}

A operação cartográfica remete, inicialmente, a um dos axiomas norteadores da proposta ontológica erigida no trabalho conjunto de Deleuze e Guattari, em Mil Platôs (2007a) e em O anti-Édipo (2011). Os autores nos apresentam uma concepção do campo social que primeiramente nega análises binárias e dicotomizadas da relação sujeito e mundo. Utilizando-se da imagem do rizoma, desdobram e afirmam a realidade como tecido constituído por materialidades e semióticas heterogêneas, perpassado por instituições, por determinações históricas, saberes, práticas, relações e desejos dispostos em arranjos provisórios, em variação contínua. Afirmam, assim, a constituição de modos de ser e a configuração do campo social procedendo por conexões e agenciamentos, pois cada nova entrada no arranjo em questão implica necessariamente uma reorganização da disposição anterior, em movimentos muito mais processuais do que identitários, mesmo que por vezes persistam sentidos rígidos estabilizados. A compreensão rizomática da realidade, apresentada aqui brevemente, nos parece um importante operador metodológico, pois a cartografia é anunciada, em Mil Platôs (2007), como um dos princípios do rizoma.

Sendo a realidade composição contínua, Deleuze e Guattari (2007a) evidenciam que, para compreender movimentos de subjetivação e modos de existência situados sob certa formação histórica, não bastariam metodologias que nos conduzissem a simples decalques, como uma fotografia capaz apenas de traçar imagens estáticas. Afirmando tanto sujeito como sociedade em devir, melhor seria recorrermos à ideia de um mapa, constituindo formas de pesquisar preocupadas com a processualidade e implicadas nas transformações que a investigação pode deflagrar. "O mapa é aberto, é conectável em todas suas dimensões, desmontável, reversível, suscetível de receber modificações constantemente" (DELEUZE; GUATTARI, 2007a, p. 22).

$\mathrm{O}$ princípio da cartografia, quando apropriado por pesquisadores do campo da psicologia (PASSOS; KASTRUP; ESCOSSIA, 2009; PASSOS; KASTRUP; TEDESCO, 2014), permite a construção de estratégias de investigação qualitativa dispostas a problematizar a subjetivação como descentrada da interioridade, como movimento, produzida no entrecruzamento de determinações diversas, que dão forma simultaneamente ao campo so- 
cial e aos modos de experimentar a condição de sujeito. $\mathrm{O}$ ser, sob este enfoque, deve ser considerado como constante processo de individuação metaestável, numa série interminável de estados de equilíbrio parciais e indivisível daquilo que o cerca (SIMONDON, 1993).

Para apreender tais movimentos, a cartografia apresenta em seu mote a busca constante pelo reconhecimento das conexões que dão formas variáveis às subjetividades, alem de destacar, em seu posicionamento ético, o protagonismo dos participantes na pesquisa. Assim, busca a construção de sentidos gestados entre pesquisadores e pesquisados, engajando ambos em movimentos voltados à transformação das possibilidades de nomear e experimentar a realidade investigada. Cartografar, nas palavras de Barros e Kastrup (2009, p. 53), "consiste no acompanhamento de processos, e não na representação de objetos".

Passos, Kastrup e Escossia (2009) e Kastrup (2009) nos fornecem mais uma importante pista para a compreensão da perspectiva cartográfica: afirmam, em distintos trabalhos, a prática do método cartográfico como um fazer sustentado por uma política cognitiva construtivista. No lugar de uma suposta neutralidade, de uma cisão entre sujeito e objeto que isola o estudado de suas conexões para fragmentá-lo em partes, a cartografia propõe-se ao movimento contrário: o cartógrafo visa ao sentido de seu objeto no entre (entre dois, entre grupos e sociedade, entre pesquisador e pesquisado, entre passado e presente), apostando em uma lógica onde "pesquisar com" substitui o "pesquisar sobre" (TEDESCO, 2015).

Uma política cognitiva pressupõe uma política da pesquisa. A cartografia caracteriza-se como ato político desde que consideremos o político não como gestão das coletividades ou negociação das divisões já instauradas em busca de consensos pacificadores. A política se evidência, ao contrário, quando são verificáveis movimentos capazes de criar brechas nos modos de apresentação do real, que engendrem novas configurações ao pensamento e ao campo de experiências. A política deve ser lida, desta maneira, como movimento ligado à subjetivação, à abertura de campos de sentido inéditos que disponham no comum novas configurações (RANCIÈRE, 1996).

A política cognitiva construtivista, situada como princípio da cartografia, nos leva diretamente à reflexão sobre uma das grandes questões transversais à filosofia de Gilles Deleuze e que, sem dúvida, é inspiração ao método: o que significa pensar? Em boa parte de sua obra, e mais especialmente em Diferença e Repetição (2009) e em $O$ que é Filosofia? (2007b), escrito com Guattari, Deleuze empreende uma pesada crítica às heranças do platonismo que sustentam uma filosofia e uma racionalidade baseadas na representação, que por consequência perpetuam a crença em um mundo já dado. Bastaria, se consideradas as premissas platônicas, ao sujeito que deseja apreender o mundo, a recognição e um caminho metodológico homogêneo para que se identifique o verdadeiro e se distinga este do falso. Pela via da Filosofia da Diferença, dialogando com Espinosa, Nietzsche e Foucault (entre outros,

como Hume, Bergson, Simondon e Kant), Deleuze nos apresenta outra imagem do pensamento, afirmando um pensar não naturalizado.

A condição para problematizar as naturalizações e para ultrapassar as verdades consentidas estaria sujeita à qualidade dos encontros que experimentamos em nossa existência. $\mathrm{O}$ trabalho do pensamento, situado na trama relacional entre pesquisadores e pesquisados, portanto, remete a uma política de produção de conhecimento que investe na emergência de outros mundos possíveis e, por isso, não se separa da intervenção em nenhum de seus movimentos. "É o encontro contingente com o que força a pensar, com o que faz pensar, que produz a necessidade absoluta de um ato de pensamento; é a ação das forças efetivas, de determinações externas sobre o pensamento, que força a pensar" (MACHADO, 2013, p. 150). Pensar, então, é construir e é também criar. Significa elaborar, na intensidade das afecções que movem o próprio pensamento, desvios e expressões inéditas em relação ao que, até então, era tomado como comum e invariável. A possibilidade de reconhecer diferenças na realidade só emerge nos encontros com potência criadora e, por consequência, carrega consigo potência política.

Uma metodologia de pesquisa e de intervenção disposta a produzir não pode ignorar o imperativo ético dos bons encontros. ${ }^{2}$ Por isso, precisa engendrar relações que rompam com as hierarquias instituídas, em busca da transversalidade entre distintas perspectivas e da intersecção de práticas diversas.

A pesquisa cartográfica é proposta metodológica que só se operacionaliza se for erigido, na relação pesquisador-pesquisado-contexto, um agenciamento, enquanto campo de experiências que antes não era acessível a nenhuma das partes. É necessário à pesquisa cartográfica o traçado de um "plano comum” (KATRUP; PASSOS, 2013), no qual se reconheça e se valorize a heterogeneidade de práticas e discursos e seus desdobramentos em novos pensamentos e novas formas de relação.

É neste ponto da reflexão que propomos intersecções entre a pesquisa cartográfica e a construção de dispositivos de intervenção nas práticas da psicologia social. A filosofia da diferença, assim como no método cartográfi$\mathrm{co}$, vem constituindo aporte teórico profícuo à psicologia social no Brasil. Destas leituras emergem trabalhos voltados a deflagrar movimentos de resistência e criação. O termo resistência pode sugerir uma conotação negativa, quando ligado ao confronto, à oposição ou mesmo a ausências de movimento. Aqui procuramos por interpretações diferentes destas, que nos ajudem a pensar a resistência como movimento de composição com os materiais sensíveis, por práticas variáveis, que, como afirmam Zanella, Levitan e Almeida (2012, p. 258), se constituem em "resistência inventiva, propositiva, que não sucumbe

\footnotetext{
${ }^{2}$ Espinosa (1992) situa o plano ético no campo das afecções, dos múltiplos encontros possíveis entre corpos e entre pensamentos. Bons encontros, nesta perspectiva, são aqueles capazes de potencializar a vida, sustentados por relações de composição entre as diferenças, que ampliem as possibilidades de pensar e agir. Suas contribuições são referências imprescindíveis à compreensão do pensamento de Gilles Deleuze.
}

Fractal, Rev. Psicol., v. 32 - n. 1, p. 64-71, 2020 
frente a uma moral hegemônica". Resistência, portanto, como sinônimo de invenção de novos possíveis, como re-existência.

Tais leituras mobilizam a busca por intervenções pensadas para potencializar a atividade criadora, o trabalho dissensual do pensamento e a emancipação das coletividades.

A noção de dispositivo, que apresentaremos no tópico seguinte, nos serve como um guia para expor tais experiências e abre caminho ao traçado de possibilidades para o método cartográfico na intervenção em psicologia social.

\section{Dispositivos de intervenção da Psicologia Social e o fazer cartográfico}

As intervenções da psicologia no Brasil, tendo como norte a área da psicologia social, seguindo o ideário da Associação Brasileira de Psicologia Social (ABRAPSO), se desenvolvem em contextos diversos, que apresentam problemáticas distintas, e por isso nos exigem estratégias de ação também diversificadas. Trabalhos em comunidades, junto às políticas públicas de educação, assistência social e saúde, em cooperativas fundadas sob a lógica da economia solidária, em movimentos sociais e inúmeras outras experiências, fazem ver a abrangência desse campo de saber para a atuação da psicologia.

A multiplicidade de nossas intervenções não significa incongruência, pois é sustentada historicamente por pressupostos éticos e políticos que afirmam um compromisso social como princípio unificador. A dimensão ética que permeia tais trabalhos diz respeito à necessidade de que sejam criados espaços relacionais direcionados à equidade, ao respeito e valorização dos distintos saberes, dedicados à produção de encontros que aumentem a potência de ação dos coletivos (GUATTARI, 2006). A dimensão política refere-se à constante atitude dissensual na gênese de negociações sobre sentidos, lugares e capacidades que são atribuídos a distintos sujeitos e a diferentes práticas em uma comunidade (RANCIËRE, 1996). Estes pressupostos não podem ser descolados de uma dimensão estética, que toca a política. O estético diz respeito à dimensão sensível de nossas experiências, ao recorte de tempos e espaços que sustentam a visibilidade ou a invisibilidade de um comum partilhado (RANCIÈRE, 1996). Refere-se, ainda, aos enunciados e às condições de compreensão do dito como expressão tomada como válida e verdadeira em uma comunidade quando relacionada a seus conteúdos (DELEUZE, 1974).

É em função de tais diretrizes que a psicologia social recorre, em seu trabalho, à reinvenção constante de intervenções que buscam a gênese de processos de subjetivação inéditos, em cada contexto de trabalho. Este movimento, entendemos, pode ser enriquecido pelas contribuições cartográficas, visando à construção de dispositivos de intervenção, tomados como arranjos relacionais e dialógicos capazes de mover o pensamento a direções inéditas, pela produção de encontros singulares. Compreender os distintos arranjos produtores de dispositivos faz-se então fundamental no traçado de conexões entre a prática cartográfica e a dimensão interventiva que aqui discutimos.

Fractal, Rev. Psicol., v. 32 - n. 1, p. 64-71, 2020
Deleuze (1990, p. 155) entende dispositivo como "máquina de fazer ver e fazer falar". Sua leitura do conceito remete tanto à construção de dispositivos mobilizadores de mudanças quanto à análise daqueles já instituídos e reguladores das formas de vida. A produção de novos dispositivos indica um movimento que precisa ser construído caso a caso, em que é possível "traçar um mapa, cartografar, percorrer terras desconhecidas" (DELEUZE, 1990, p. 155) na busca por desdobramentos que permitam ultrapassar as formas consensuais e hegemônicas de subjetivação.

A noção de dispositivo pode ser situada em duas leituras distintas, mas complementares quando visamos à produção de arranjos cartográficos que potencializem encontros. A primeira, desenvolvida por Foucault (1984), nos remete aos dispositivos disciplinares e de controle. Em seus trabalhos, os dispositivos disciplinares são entendidos como uma complexa rede de elementos heterogêneos que dissocia os corpos e as subjetividades de suas múltiplas capacidades, conjugando instituições, racionalidades científicas, práticas regulamentadas, conjuntos arquitetônicos e moralidades em torno da produção de formas de ser específicas. Dispositivos disciplinares, então, não podem ser lidos apenas a partir de sua objetividade. Compreendê-los depende da apreensão de sua multiplicidade, que normaliza formas de ser e agir, instaurando verdades no campo social e constituindo a percepção de um comum inquestionável, naturalizado.

As análises foucaultianas sobre a produção de tais arranjos é vasta. Mesmo que não possamos nos estender em torno desta questão aqui, podemos tomar como exemplo a ressignificação da loucura como objeto médico-psiquiátrico e a produção concomitante de um conjunto arquitetônico destinado a seu enclausuramento no século XVII (FOUCAULT, 1978), assim como a aproximação do discurso psiquiátrico ao jurídico na construção de redes de saber/poder (FOUCAULT, 1997). Destaca-se, ainda, a vigilância e o controle permanente dos corpos no panoptismo do sistema prisional, que induz ao reconhecimento de um controle total, exposto pelo mesmo autor em Vigiar e Punir (1997). Nas palavras de Fanlo (2011, p. 3), os dispositivos disciplinares de Foucault seriam arranjos instaurados no campo social que "determinam tipos de classificação de sujeitos, objetos e relações entre estes, um jogo de relações discursivas e não discursivas [...] que produzem sujeitos que, como tais, estão assujeitados a determinados efeitos de saber/poder.

Esses arranjos materiais e simbólicos são organizados de modo a produzir dois processos concomitantes que evidenciam modos de subjetivação privados da potência necessária para que se configurassem resistências: por um lado, possibilitam a manutenção de distintas formas de sujeição, reiterando identidades autorreferentes constituídas na produção de um reconhecimento de si, gestadas na demarcação de lugares determinados pela ordem do discurso e no plano dos saberes de certo momento histórico (FOUCAULT, 1986); por outro, geram assujeitamento dos corpos, que se docilizam. Como duplo movimento de captura das subjetividades, evidenciam 
corpo e pensamento, no fluxo circular de um conjunto de práticas e relações demarcadas por instituições, por suas práticas e discursos. A leitura foucaultiana expressa um processo de subjetivação descentrado do indivíduo, capaz de nomeá-lo e fazê-lo agir, em um exercício difuso que pressupõe divisões operadoras no entrecruzamento de relações de poder, de capacidades objetivas e relações de comunicação (FOUCAULT, 1995, p. 240). Discursos e práticas instituídos e formações históricas delineadas constituem tal circularidade, fazendo convergir possibilidades de nomear e ser nomeado sob um mesmo plano imanente, mas perpetradas por atribuições destinadas a lugares distintos, objetivadas em conteúdos e expressões que se retroalimentam e geram reprodução.

O dispositivo de controle, então, pode ser compreendido por suas conexões estáveis, pelos agenciamentos que são traçados entre uma série de elementos heterogêneos. Cabe aqui destacar que não são os elementos expressivos e as formas dos conteúdos que definem o dispositivo de forma isolada, mas sim a configuração de um arranjo complexo entre eles.

Os dispositivos, da forma como são enunciados por Foucault, podem ser lidos como aparelhos de captura, como catalisadores das formas de vida que, antes possuidoras de uma potencialidade infinita, são comprimidas a um campo de possíveis delimitado e passam a ser finitas e localizáveis.

A segunda leitura possível da noção remete à montagem de novos dispositivos, que aqui chamaremos de "dispositivos de intervenção". Estes permitam ver, falar, pensar e fazer de maneiras distintas daqueles determinados pelas condições já dadas. Gilles Deleuze abre uma brecha fundamental à leitura foucaultiana quando insere "a produção no desejo e o desejo na produção" em $O$ anti-Édipo, junto a Félix Guattari (2011). O desejo, não mais visto como expressão de falta, mas sim como potência criadora, quando agenciado por forças que escapam daquelas sobrepostas na série componente dos dispositivos de controle, pode engendrar modos de vida que resistam às modelações hegemônicas. Na sua obra exclusiva O desejo e o prazer (1993), Deleuze aponta, ainda, para movimentos de resistência aos dispositivos disciplinares que capturam, situando em um eixo paralisante a submissão do desejo aos estados de coisa e enunciações já postos, e em outro eixo a atividade criadora, que extrapola o dado e engendra formas e conteúdos inéditos. "Conforme um outro eixo [o segundo], seriam distinguidas as territorialidades ou reterritorializações e os movimentos de desterritorialização que desencadeiam um agenciamento" (DELEUZE, 1993, p. 3). No mesmo texto, o autor complementa seu argumento:

De minha parte, diria o seguinte: uma sociedade, um campo social não se contradiz, mas ele foge, e isto é primeiro. Ele foge de antemão por todos os lados; as linhas de fuga é que são primeiras (mesmo que primeiro não seja cronológico). Longe de estar fora do campo social ou dele sair, as linhas de fuga constituem seu rizoma ou cartografia. As linhas de fuga são quase a mesma coisa que os movimentos de desterritorialização: elas não implicam qualquer retorno à natureza; elas são as pontas de desterritorialização nos agenciamentos de desejo (DELEUZE, 1993, p. 5).

Esta segunda leitura, imbricada à compreensão da primeira, nos serve como ferramenta de trabalho da psicologia. Consideramos, a partir da torção operada por Deleuze na noção de dispositivo, a possibilidade de que, em nossas intervenções, sejam constituídos campos de relações inéditas, que permitam o surgimento de novas experiências. Se os dispositivos disciplinares produzem corpos dóceis e subjetividades identitárias engendradas na sujeição e no assujeitamento, entendemos como possível a emergência de outras modalidades de encontros entre corpos e a produção dialógica de novos enunciados, capazes de fazer pulsar linhas de fuga, que resistam à imobilidade.

Se Foucault nos faz compreender como um dispositivo disciplinar gera linhas de visibilidade e de dizibilidade que tornam imóveis e identitárias as subjetividades, Deleuze e alguns de seus interlocutores nos apresentam estratégias de resistência e de abertura. Reposicionar grupos e experiências no campo da processualidade desviante é imperativo dos dispositivos de intervenção em psicologia. Assim, propomos combater a conexão estática de um conjunto heterogêneo, justamente pela heterogênese que faz emergirem arranjos inéditos. Propomos que se possam abrir os dispositivos de captura, capturando por outras vias as lógicas de tais dispositivos e maquinando fugas. Se a captura normalizadora faz concorrerem elementos heterogêneos em um campo estável que paralisa, investir na heterogeneidade dos elementos que podem compor outras subjetividades diz respeito a um plano inédito, que considera como fundamental a experimentação coletiva como motora de (re)composições incessantes. Sustentar esta lógica de intervenção é possível "desde que entendamos o termo heterogênese como a composição a partir de elementos diferentes das amarras consensuais que delimitam territórios unívocos e aparentemente estáveis do visível, do possível e do pensamento" (CAVAGNOLI; MAHEIRIE, 2015). A intervenção se faz inventiva, portanto, sob certas condições, quando alçamos voo em direção a estratégias de ação e de diálogo capazes não apenas de representar e repetir, mas de apresentar realidades em devir, em transformação, considerando as diferenças e potências de nossos encontros imanentes.

Domênico Hur (2012), interpretando a criação de dispositivos a partir do Esquizodrama, apresenta contribuições significativas ao nosso trabalho. O autor afirma os movimentos de um dispositivo como agenciamento de linhas de saber, poder e subjetivação, incorporando ao seu trabalho a lógica foucaultiana e a abertura deleuziana que há pouco enunciamos. A preocupação de Hur (2012), assim como a nossa, é expor uma estratégia de desmontagem dos dispositivos que capturam, através da apresentação de outros dispositivos possíveis, forjados na intersecção entre grupo e quem intervém. Preocupado em descrever a capacidade de transformações do campo sensível compartilhado, inerente à montagem de uma intervenção, o autor define os dispositivos criadores como "uma máquina de produção de discursos e de ações-re- 
lações, em que se faz 'falar' e se faz 'ver', produzindo enunciações, visibilidades distintas, acontecimentos e modos de ser" (HUR, 2012, p. 21). Por tal via, sustenta que a montagem de dispositivos depende da criação de um campo discursivo inédito e de possibilidades de encontros entre corpos e objetividades que extrapolem as possibilidades oferecidas pelo cotidiano que se reitera. Concordamos com tal perspectiva, pois suas considerações fazem repercutir o que antes consideramos como dimensão ética e estética de uma intervenção.

Se intervir é sinônimo de abertura a um novo conjunto de possíveis antes virtuais, se o trabalho da psicologia atualiza realidades antes impensáveis, constitui-se, inevitavelmente, como construção negociada caso a caso, destinada a escapar de concisos arranjos que sintetizam, de modo conjuntivo, o heterogêneo, impedindo os devires criadores. Salientamos aqui que não há como fugir sem saber de que se escapa, sem problematizar a configuração de arranjos que impossibilitam aberturas. Por isso se faz imprescindível cartografar o conjunto de condições existenciais atualizadas em um universo sensível comum e compartilhado. É em função deste ponto que a contribuição foucaultiana se faz fundamental para que se tracem cartografias dos arranjos estáticos presentes nos mais diversos contextos.

Faz-se impossível produzir dispositivos de intervenção sem antes cartografar o conjunto heterogêneo de forças que opera na estabilização impeditiva da variação dos devires. Do mesmo modo, é impossível intervir sem cartografar o plano que se constitui durante a própria intervenção, como um movimento de abertura que precisa ser reconhecido pelo coletivo implicado em tal projeto emancipatório. A proposta cartográfica potencializa uma ética dos encontros, o reconhecimento do jogo hegemônico entre expressão e conteúdo e suas possíveis variações. Esta postura, esperamos, reafirma a indelével conexão entre pesquisar e intervir, potencializando a política construtivista da cartografia e o compromisso social que perpassa o trabalho da psicologia social, em uma perspectiva crítica brasileira.

\section{Considerações finais}

O pesquisar, como proposto pelo método cartográfico, engendra formas de relação que permitem compreender o campo, acompanhar as condições da construção de um plano comum, polifônico, ${ }^{3}$ de diálogo e ocupação de espaços e tempos gerados durante a intervenção. A reflexão oferecida pelo método ainda oferece condições de registrar, analisar e avaliar o trabalho que se desenvolve, permitindo o compartilhamento de experiências promissoras ou de problemáticas fundamentais. O paradigma ético, estético e político que sustenta o intervir, por meio da construção de dispositivos criadores, dialoga de forma profícua com o método cartográfico.

\footnotetext{
${ }^{3}$ Entendemos a noção de polifonia a partir de sua construção na obra de Mikhail Bakhtin (2008). O autor se utiliza do termo para referir-se a uma dimensão essencial de qualquer situação dialógica que vise a ampliação de sentidos e a abertura de possibilidades à compreensão. A polifonia, assim, remete ao encontro entre uma multiplicidade de vozes que, apesar de enunciarem perspectivas distintas, o fazem em condição de igualdade, combinando-se e ultrapassando a posição dos interlocutores quando isolados.
}

Fractal, Rev. Psicol., v. 32 - n. 1, p. 64-71, 2020
Deste modo, entendemos os dispositivos de intervenção como objetivações práticas e discursivas, criadas caso a caso quando sua produção é pautada por uma ética dos encontros, com o objetivo de dar vazão a movimentos de subjetivação e objetivação. O conhecimento das conexões e dos agenciamentos que dão forma a cada contexto de intervenção exige uma postura de pesquisa ativa, de cruzamento entre distintos pontos de vista e um reconhecimento ético-político da multiplicidade de vozes entrecruzadas em uma experiência coletiva. Pela via ética e política é que sustentamos nossa reflexão, esperando oferecer elementos que permitam o desdobramento de práticas no âmbito da psicologia conectadas ao método cartográfico, que sustentem caminhos de compreensão e enfrentamento das demandas e problemáticas contemporâneas.

\section{Informações sobre os autores:}

\section{Murilo Cavagnoli \\ (iD) https://orcid.org/0000-0003-0363-3017 \\ (9) http://lattes.cnpq.br/3250921935613216}

Psicólogo, mestre e doutor em Psicologia pela Universidade Federal de Santa Catarina. Atualmente é professor na Universidade Comunitária Regional de Chapecó (Unochapecó), onde atua no ensino, pesquisa e extensão. Tem experiência na área de Psicologia, com ênfase em Psicologia Social, atuando principalmente nos seguintes temas: psicologia social, estética, política e processos de criação, produção de subjetividade, música, arte e intervenção psicológica no contexto das políticas públicas de assistência social e saúde.

\section{Katia Maheirie \\ (iD) https://orcid.org/0000-0001-5226-0734 \\ (9) http://lattes.cnpq.br/7689469021584393}

Kátia Maheirie é graduada em Psicologia pela UFSC, com mestrado e doutorado em Psicologia Social pela Pontifícia Universidade Católica de São Paulo. Fez estágio pós doutoral em Educação na UNICAMP e em Psicologia Social na Universitat Autónoma de Barcelona (ES) e na PUC/SP. É Professora Titular da Universidade Federal de Santa Catarina, no Departamento e no Programa de PósGraduação em Psicologia (PPGP). É Pesquisadora Produtividade do $\mathrm{CNPq}$, atuando no Núcleo de Pesquisa em Práticas Sociais, Estética e Política, onde desenvolve trabalhos de pesquisa e extensão voltados a estética e política em diferentes contextos sociais. Foi editora da Revista Psicologia \& Sociedade de 2008 a 2011 e foi editora geral da Revista de Ciências Humanas (UFSC). Assumiu recentemente a editoria geral da revista Psicologia Política (2020-2023). Foi membro da Comissão Qualis Periódicos da CAPES 2015-2017. É membro da Diretoria da Associação Nacional de Pesquisa e Pós-Graduação em Psicologia (20182020). Suas investigações são na área de Psicologia Social, com ênfase em estética, música, política, movimentos sociais, ações coletivas e políticas de assistência social. Em seu currículo Lattes os termos mais freqüentes na contextualização da produção científica, tecnológica e artístico-cultural são: processos de criação, estética, música, política, oficinas estéticas, identidade coletiva; movimentos sociais; e CRAS.

\section{Contribuições dos autores:}

Todos os autores colaboraram ao longo do processo, desde a elaboração até a revisão final do manuscrito. Os autores aprovaram o manuscrito final para publicação. 
Como citar este artigo:

ABNT

CAVAGNOLI, Murilo; MAHEIRIE, Kátia. A cartografia como estratégia metodológica à produção de dispositivos de intervenção na Psicologia Social. Fractal: Revista de Psicologia, Niterói, v. 32, n. 1, p. 64-71, jan./abr. 2020. https://doi.org/10.22409/1984-0292/ v32i1/5680

\section{APA}

Cavagnoli, M., \& Maheirie, K. (2020, Janeiro/Abril). A cartografia como estratégia metodológica à produção de dispositivos de intervenção na Psicologia Social. Fractal: Revista de Psicologia, 32(1), 64-71. doi: https://doi.org/10.22409/1984-0292/v32i1/5680

\section{Referências}

BAKHTIN, Mikhail. Problemas da poética de Dostoiévski. Trad. Paulo Bezerra. Rio de Janeiro: Forense Universitária, 2008.

BAUMAN, Zygmunt. Modernidade Líquida. Rio de Janeiro: J. Zahar, 2001.

BARROS, Laura Pozzana de; KASTRUP, Virgínia. Cartografar é acompanhar processos. In: PASSOS, Eduardo; KASTRUP, Virgínia; ESCOSSIA, Liliana. Pistas do método da Cartografia. Porto Alegre: Sulina, 2009. p. 52-75

BENEVIDES, Regina. A Psicologia e o Sistema Único de Saúde: quais interfaces? Psicologia \& Sociedade, Porto Alegre, v. 17 , n. 2, p. 21-25, 2005. http://dx.doi.org/10.1590/S010271822005000200004

BERNARDES, Jefferson de Souza. História. In: STREY, Marlene Neves et al. (Org.). Psicologia social contemporânea: livro texto. 12 ed. Petrópolis: Vozes, 2009. v. 1, p. 10-30.

BOCK, Ana Mercês Bahia. A psicologia e o caminho do novo século: identidade profissional e compromisso social. Estudos em Psicologia, Natal, v. 4, n. 2, p. 315-329, 1999. https://doi. org/10.1590/S1413-294X1999000200008.

BOCK, Ana Mercês Bahia. Psicologia Social e as Políticas Públicas. In: TATSCH, Dirce T.; GUARESCHI, Neuza M. F.; BAUMKARTEN, Silvana T. (Org.). Tecendo Relações $e$ Intervenções em Psicologia Social. Porto Alegre: ABRAPSO SUL, 2009. v. 1, p. 174-182.

BOCK, Ana Mercês Bahia; GONÇALVEZ, Maria da Graça Marchina. FURTADO, Odair. Psicologia sócio-histórica: uma perspectiva crítica em psicologia. 5 ed. São Paulo: Cortez, 2001.

CAMPOS, Regina Helena de Freitas. Psicologia social comunitária: da solidariedade à autonomia. Petrópolis: Vozes, 1985.

CAVAGNOLI, Murilo; MAHEIRIE, Katia. Heterogênese e regime estético da arte: a composição do sensível e a política da estética na criação musical. In: VOJNIAK, F. (Org.). História e linguagens: historiografia, memórias e política. São Paulo: Paco Editorial, 2015. p. 205-228.

DELEUZE, Gilles. Lógica do sentido. Trad. Luiz Roberto Salinas Fortes. São Paulo: Perspectiva, 1974.

DELEUZE, Gilles. ¿Que és un dispositivo? In: Michel Foucault, filósofo. Barcelona: Gedisa, 1990. p. 155-161.

DELEUZE, Gilles. Desejo e prazer. In: PELBART, P; ROLNIK, S. (Org.). Cadernos de Subjetividade, PUC/São Paulo, v. 1, n. 1, p. 13-25, 1993.
DELEUZE, Gilles. Diferença e repetição. São Paulo: Graal, 2009.

DELEUZE, Gilles; GUATTARI, Félix. Mil Platôs: capitalismo e esquizofrenia. Rio de Janeiro: Editora 34, 2007a. v. 1.

DELEUZE, Gilles; GUATTARI, Félix. $O$ que é a Filosofia? Rio de Janeiro: Editora 34, $2007 \mathrm{~b}$.

DELEUZE, Gilles; GUATTARI, Félix. $O$ anti-édipo: capitalismo e esquizofrenia. São Paulo: Editora 34, 2011.

ESPINOSA, Baruch. Ética. Lisboa: Relógio d'agua, 1992.

FANLO, Luis Garcia. Que és un dispositivo? Foucalt, Deleuze y Agambem. A Parte Rei. Revista de Filosofia, Madrid, n. 74, p. 1-8, 2011. Disponível em: https://www.aacademica.org/luis. garcia.fanlo/2. Acesso em: 22 mar. 2018.

FIGUEIREDO, Luís Cláudio. Convergências e divergências: a questão das correntes de pensamento em psicologia. São Paulo: Transformações, 1992.

FOUCAULT, Michel. História da loucura na idade clássica. São Paulo: Perspectiva, 1978.

FOUCAULT, Michel. El Juego de Michel Foucault. In: Saber y Verdad. Madrid: Ediciones de la Piqueta, 1984. p. 127162.

FOUCAULT, Michel. A arqueologia do saber. Rio de Janeiro: Forense, 1986.

FOUCAULT, Michel. Apêndice: o sujeito e o poder. DREYFUS, Hubert; RABINOW, Paul (Org.). Uma trajetória filosófica: para além do estruturalismo e da hermenêutica. São Paulo: Forense, 1995.

FOUCAULT, Michel. Vigiar e Punir: o nascimento da prisão. Petrópolis, Vozes, 1997.

FREIRE, José Célio. As psicologias na modernidade tardia: o lugar vacante do Outro. Psicologia USP, São Paulo, v. 12, n. 2, p. 73-93, 2001. https://doi.org/10.1590/S010365642001000200005

GIDDENS, Anthony. As consequências da modernidade. São Paulo: Unesp, 1991.

GUATTARI, Félix. As três ecologias. São Paulo: Papirus, 2006.

HALL, Stuart. Identidade cultural na pós-modernidade. Rio de Janeiro: Lamparina, 2014.

HARVEY, David. Condição pós-moderna. São Paulo: Loyola, 2013.

HUR. Domenico Uhng. Odispositivo de grupo na esquizoanálise: tetravalência e esquizodrama. Vínculo, São Paulo, v. 9, n. 1, p. 18-16, 2012. Disponível em: http://pepsic.bvsalud.org/scielo. php?script=sci_arttext\&pid=S1806-24902012000100004\&lng =pt\&nrm=iso. Acesso em: 12 out. 2019.

KASTRUP, Virgínia. O funcionamento da atenção no trabalho do cartógrafo In: PASSOS, Eduardo; KASTRUP, Virgínia; ESCOSSIA, Liliana. Pistas do método da Cartografia. Porto Alegre: Sulina, 2009. p. 32-51.

KASTRUP, Virgínia; PASSOS, Eduardo. Cartografar é traçar um plano comum. Fractal: Revista de Psicologia, Rio de Janeiro, v. 25, n. 2, p. 263-280, 2013. https://doi.org/10.1590/ S1984-02922013000200004

LANE, Silvia Tatiana Maurer; CODO, Wanderlei. Psicologia social: o homem em movimento. 2. ed. São Paulo: Brasiliense, 1985.

Fractal, Rev. Psicol., v. $32-$ n. 1, p. 64-71, 2020 
MACHADO, Roberto. Deleuze: a arte e a Filosofia. Rio de Janeiro: Zahar, 2013.

PASSOS, Eduardo; BARROS, Regina Benevides. A Cartografia como método de pesquisa-intervenção. In: PASSOS, Eduardo; KASTRUP, Virgínia; ESCOSSIA, Liliana. Pistas do método da Cartografia. Porto Alegre: Sulina, 2009. p. 17-31.

PASSOS, Eduardo; KASTRUP, Virgínia; ESCOSSIA, Liliana. Pistas do método da Cartografia. Porto Alegre: Sulina, 2009.

PASSOS, Eduardo; KASTRUP, Virgínia; TEDESCO, Silvia. Pistas do método da Cartografia: a experiência da pesquisa e o plano comum. Porto Alegre: Sulina, 2014.

RANCIÈRE, Jacques. $O$ desentendimento: política e filosofia. São Paulo: Editora 34, 1996.

REIS, Alice Casanova dos. ZANELLA, Andréa Vieira. Psicologia Social no campo das políticas públicas: oficinas estéticas e reinvenção de caminhos. Revista de Ciências Humanas, Florianópolis, v. 49, n. 1, p. 17-34, 2015. https://doi. org/10.5007/2178-4582.2015v49n1p17

SIMONDON, Gilbert. A gênese do indivíduo. Cadernos de subjetividade. Núcleo de Estudos e Pesquisas da Subjetividade do Programa de Pós-Graduados em Psicologia Clínica, PUC/ São Paulo, v. 1, n. 1, p. 164-175, 1993.

TEDESCO, Silvia. A ética da pesquisa e a perspectiva da cartografia: algumas considerações. Revista Polis e Psique, v. 5, n. 2, p. 32-47, 2015. https://doi.org/10.22456/2238-152X.53952

ZANELLA, Andréa Vieira; LEVITAN, Déborah; ALMEIDA, Gabriel Bueno; FURTADO, Janaina Rocha. Sobre reXistências. Revista Psicologia Política, São Paulo, v. 12, n. 24. p. $247-$ 262, 2012. Disponível em: http://pepsic.bvsalud.org/scielo. php?script=sci_arttext\&pid=S1519-549X2012000200005\&lng =pt\&nrm=iso. Acesso em: 17 fev. 2019. 